\title{
DESIGNING OF WATER DISTRIBUTION SYSTEM
}

\author{
Osama Khasraw Mohammed Amin \\ MSc student, University of Miskolc, Institute of Logistics \\ 3515 Miskolc, Miskolc-Egyetemváros,e-mail:khosama98@gmail.com \\ Mohammad Zaher Akkad \\ PhD student, University of Miskolc, Institute of Logistics \\ 3515 Miskolc, Miskolc-Egyetemváros, e-mail: zaherakkad91@gmail.com \\ Tamás Bányai \\ associate professor, University of Miskolc, Institute of Logistics \\ 3515 Miskolc, Miskolc-Egyetemváros,e-mail: alttamas@uni-miskolc.hu
}

\begin{abstract}
Water distribution system (WDS) aims to distribute water from reservoirs or aqueducts to the end-users. This system is part of the water supply network that carries potable water from a central treatment plant or wells to water consumers in order to deliver water sufficiently to meet residential, commercial, industrial, and firefighting requirements. Modern systems aim to solve water distribution systems management problems, such as the lowest cost, and most efficient design by using linear/nonlinear optimization schemes, which are limited by the system size, the number of constraints, and the number of loading conditions. After a literature review for the articles that dealt with this topic, designing two parts of the water distribution system is discussed as a case study in Erbil. Pumps and storage tanks, while optimizing the water distribution system by minimizing the project cost through minimizing the volume of the elevated tank according to the pump working hours.
\end{abstract}

Keywords: water distribution system, optimization, distribution design

\section{Introduction}

Water distribution networks should cover the urban areas to provide clean water to all facilities, public services, and buildings. Water should be available seven days a week without interruption, at a pressure that should be sufficient to supply the upper water tanks in the various buildings. For this reason, the construction of groundwater tanks in the new residential buildings, which are in the covered areas by water networks is no longer necessary, and it is advised to suffice with upper water tanks that are directly connected to the supply line from the water distribution network. However, in areas where the water supply may be intermittent, it is recommended to build ground tanks that hold enough water for about one week's consumption. The water is raised from the ground tank to the upper tank by using an electric pump.

Within the water distribution network, different parts should work accurately for efficient usage, such as the water tanks and pumps. A water tank is a site constructed and designated for storing water. It is also used sometimes to provide and store rain and rivers water for drinking, agriculture, irrigation, fire suppression, and other beneficial uses, whether for plants or livestock, or chemical industries, food 
preparation, as well as many other applications. There are small tanks in every house for washing and drinking purposes. Different materials are used to make the water tank such as plastic material (polyethylene and polypropylene) as well as glass fibers and may use concrete, stone, and steel (welded or riveted, carbon, or stainless), and the tank may be made of clay or ground that performs the function of a pool. Most of the house tanks are placed above the house for drinking and washing purposes. The recommended location of the storage tank is the center of demand in the service area. Elevated tanks are used most frequently because it has many advantages. With using the elevated tanks, it is not required to operate the pumps continuously. Considering that the water pressure is preserved by gravity, a short pump shutdown does not affect the distribution water system pressure. The tank location plays an important role to equalize the water pressure in the distribution system. However, accurate water pressure could be difficult to manage in some elevated tanks depending on the geographical network and the distribution points locations

Pump is a mechanical device used to transfer liquids from one place to another by increasing the pressure of the fluid and supplying it with energy to travel in the pipes to the required place and this energy must be sufficient to enable the fluid to overcome the effect of friction and gravity forces. Pumps are an energy conversion machine that converts the kinetic energy of a liquid into pressure. The pumps are generally associated with an integrated system of pipes, valves, and measuring devices that ensure the safety of the pump's operation, the safety of its workers, and its ease of maintenance if necessary. There are different types of pumps such as dynamic pumps that work on continuously raising the pressure of the fluid by converting the kinetic energy of the fluid into pressure using a shaft and an impeller. This type of pump works according to the Bernoulli Principle, which states that, the pressure of the fluid increases if its velocity decreases. Therefore, these pumps first increase the velocity of the fluid using the fan or defense to obtain kinetic energy and then convert this kinetic energy into pressure by increasing the outlet area of the pump. An increase in the outlet area leads to a decrease in the fluid velocity, which in turn leads to an increase in pressure, as stated by Bernoulli's principle. Selecting the right pump depends on several factors, including the type of liquid to be compressed, the pressure to be obtained, and the cost. Therefore, WDS optimization plays an important role to achieve acceptable results.

\section{Literature review}

For having a background about the previous research that dealt with designing and optimizing the water distribution system, many articles in this area are to be discussed in this chapter.

Choi et al. improved the pipe continuity search method [1] by reducing the computation time and enhancing the ability to handle pipe size continuity at complex joints that have more than three nodes. Therefore, they could reduce the computation time by $87 \%$ and show an ability to handle complex joints. Shende et al. developed a newly meta-heuristic algorithm called the Simple Benchmarking Algorithm (SBA) [2], which was used to optimize pipe size. Modified access with SBA having interfaces with the EPANET 2.0 hydraulic simulation model was used to compute the minimum cost of the two-loop network and the Hanoi benchmark WDN. Results showed that SBA is more efficient in obtaining the least possible cost with fast convergence. Another research [3] proposed a combined genetic algorithm (GA) and linear programming (LP) method, named GALP for solving water distribution system design problems. It was investigated that the proposed method provides results that are more stable in terms of closeness to a global minimum. Olsson et al. worked on a comparison between three genetic algorithms 
[4] that use probabilistic methods to identify building blocks-the Univariate Marginal Distribution Algorithm (UMDA), the hierarchical Bayesian Optimization Algorithm (hBOA), and the Chi-Square Matrix methodology with the well-known multi-objective evolutionary algorithm NSGAII for the multiobjective design and rehabilitation of water distribution systems. Ostfeld et al. developed and demonstrated an ant colony methodology for the least-cost design of gravitational water distribution systems with a single loading case [5], to the conjunctive least-cost design and operation of multiple loading pumping water distribution systems. Judice et al. discussed an engineering optimization problem that arises in hydraulics and was related to the use of a new criterion for sizing water distribution piping in large buildings [6]. The optimization model aimed to find the most suitable interior pipe diameters for the various pipes in the system, using commercial sizes and minimizing the overall installation cost according to some boundary conditions. Babayan et al. formulated and solved the problem of stochastic water distribution system design [7] as an optimization problem under uncertainty to minimize the total design costs subject to a target level of system robustness. The sources of uncertainty analyzed here are future water consumption and pipe roughness. Kapelan et al. defined the water distribution system design problem [8] as a multi-objective optimization problem under uncertainty with two objectives that are (1) to minimize the total WDS design cost and (2) maximize WDS robustness. Gungor-Demirci et al. presented a multi-objective optimization approach that was adopted to optimize pumping operations by minimizing energy cost and greenhouse gas (GHG) emissions while considering water quality either as an additional objective or as a constraint [9].

The literature showed a wide range of research on designing and optimizing water distribution system. This verity comes from the different applications that cover various aspects. However, this research covers a case study in Erbil with define and analyze the problem and design the needed system.

\section{Define the problem with 5 whys}

To understand the problem that we face, it should be defined and analyzed in order to solve the problem and formulate the design. One of the usual tools to do that is 5 Whys.

Taiichi Ohno describes ' 5 whys' as central to the Toyota Production System methodology [10]. The basis of Toyota's scientific approach is to ask why five times whenever we find a problem. By repeating why five times, the nature of the problem as well as its solution becomes clear. This quote also makes the case for the technique's simplicity. Asking 'why' five times allows users to arrive at a single root cause that might not have been obvious at the outset. It may also inspire a single solution to address that root cause. The pedagogical argument for ' 5 whys' is that it creates an 'aah moment' by revealing the hidden influence of a distant cause, which illustrates the importance of digging deeper into a causal pathway. This quick and easy learning experience can be a powerful lesson in systems safety. In conclusion, by using it carefully, ' 5 whys' may play a powerful role. It can illustrate both the need for depth (as a positive example) and the need for breadth (as a negative example) when analyzing complex problems.

The main steps to the 5 whys are:

- Gather the working group affected by the issue in front of a whiteboard.

- Write down the problem in a detailed and clear manner.

- Ask "why the problem is occurring" five times, write the answers on the board, and make sure you distinguish symptoms from causes.

- Try to make accurate answers. 
- Identify the root cause.

- Assign responsibility for solutions and come up with five related "corrective that all the team members agree on.

In addition, other rules that should be taken into consideration:

- Look for the cause step by step. Do not jump to conclusions.

- Never leave "human error", "worker's inattention" as the root cause.

- The principal cause of dysfunction may take fewer or more than five times of asking "why".

In the following, the 5 whys technic is applied in our water distribution case study. The problem contains a residential area in Erbil that cannot find accessible water to use. The aim is to solve this problem.

Incident: A residential area in Erbil cannot find accessible water.

1. Why? Answer: There is no water distribution system in this area.

2. Why? Answer: There is a need for water distribution system design to be implemented.

3. Why? Answer: To take into consideration many points like providing enough pressure in all of the nodes, enough velocity inside the pipes, and finding an economical design for the distribution system and the elevated water tank.

4. Why? Answer: To provide enough amount of water to the consumers at the cheapest cost.

5. Why? Answer: Because without enough pressure and velocity, you cannot supply the amount of demand to the consumers and minimizing the cost of the project.

By showing the cause roots of the problem, it is more clear the need for designing and optimizing a water distribution system for that residential area.

\section{Water distribution system design and optimize}

This chapter contains two parts. Firstly, designing the pipes of the water distribution system. Secondly, design of elevated tank and pump working hours. Optimizing the cost between the volume of the elevated tank and pump working hours.

In this case study, we worked on a small residential area in Erbil, the number of houses is 1000, each house contains 5 persons, and each person needs 300 L/day.

The total daily cost:

$$
\text { Qdaily }=(1000 * 5 * 300) / 1000=1500 \mathrm{~m}^{3} / \text { day }
$$

The main source of water in this project is groundwater. In this case, drill wells provide the water. According to the efficiency of the wells in this location, each well can provide $385 \mathrm{~m} 3 / \mathrm{day}$, we have to find the number of the wells $\left(N_{w}\right)$ to provide the daily demand.

$$
N w=1500 / 385=3.896 \approx 4
$$

Therefore, a pump should carry out this amount of flow to the project.

For designing the pipes, Epanet 2.0 software is used. At first, the topography of the place is needed. Then, a good place for the elevated tank is defined. Then, creating the pipe network system according to the map of the place (Figure 1). The following tables show the results.

For designing the elevated tank, we calculate the hourly consumption demand. After getting the hourly demand of the settlement, we can find the volume of the tank and operating pump hours. 
Table 1. Pipe diameter and Discharge

\begin{tabular}{|c|c|c|c|c|c|c|c|c|c|c|}
\hline Pipe & $\mathbf{1}$ & $\mathbf{2}$ & $\mathbf{3}$ & $\mathbf{4}$ & $\mathbf{5}$ & $\mathbf{6}$ & $\mathbf{7}$ & $\mathbf{8}$ & $\mathbf{9}$ & $\mathbf{1 0}$ \\
\hline $\mathrm{D}(\mathrm{mm})$ & 50 & 50 & 50 & 100 & 50 & 100 & 50 & 50 & 100 & 100 \\
\hline Q $(1 / \mathrm{s})$ & 1.9 & 7.3 & 2.3 & 2.28 & 3.97 & 5.06 & 1.1 & 9.9 & 34.5 & 100 \\
\hline Pipe & $\mathbf{1 1}$ & $\mathbf{1 2}$ & $\mathbf{1 3}$ & $\mathbf{1 4}$ & $\mathbf{1 5}$ & $\mathbf{1 6}$ & $\mathbf{1 7}$ & $\mathbf{1 8}$ & $\mathbf{1 9}$ & \\
\hline D (mm) & 150 & 100 & 100 & 150 & 100 & 100 & 25 & 300 & 300 & \\
\hline Q (1/s) & 13.9 & 3.5 & 10 & 3.5 & 6.48 & 1.98 & 4.74 & 42 & 24.6 & \\
\hline
\end{tabular}

Table 2. Pressure in Nodes

\begin{tabular}{|c|c|c|c|c|c|c|c|c|c|c|c|c|c|c|}
\hline Nodes & 1 & 2 & 3 & 4 & 5 & 6 & 7 & 8 & 9 & 10 & 11 & 12 & 13 & 14 \\
\hline $\begin{array}{c}\text { Pressure } \\
(\mathrm{m})\end{array}$ & 24.6 & 20.6 & 19.8 & 18.5 & 19.6 & 19.6 & 22.8 & 24.7 & 22.8 & 18 & 18.2 & 20.4 & 23 & 23.6 \\
\hline
\end{tabular}

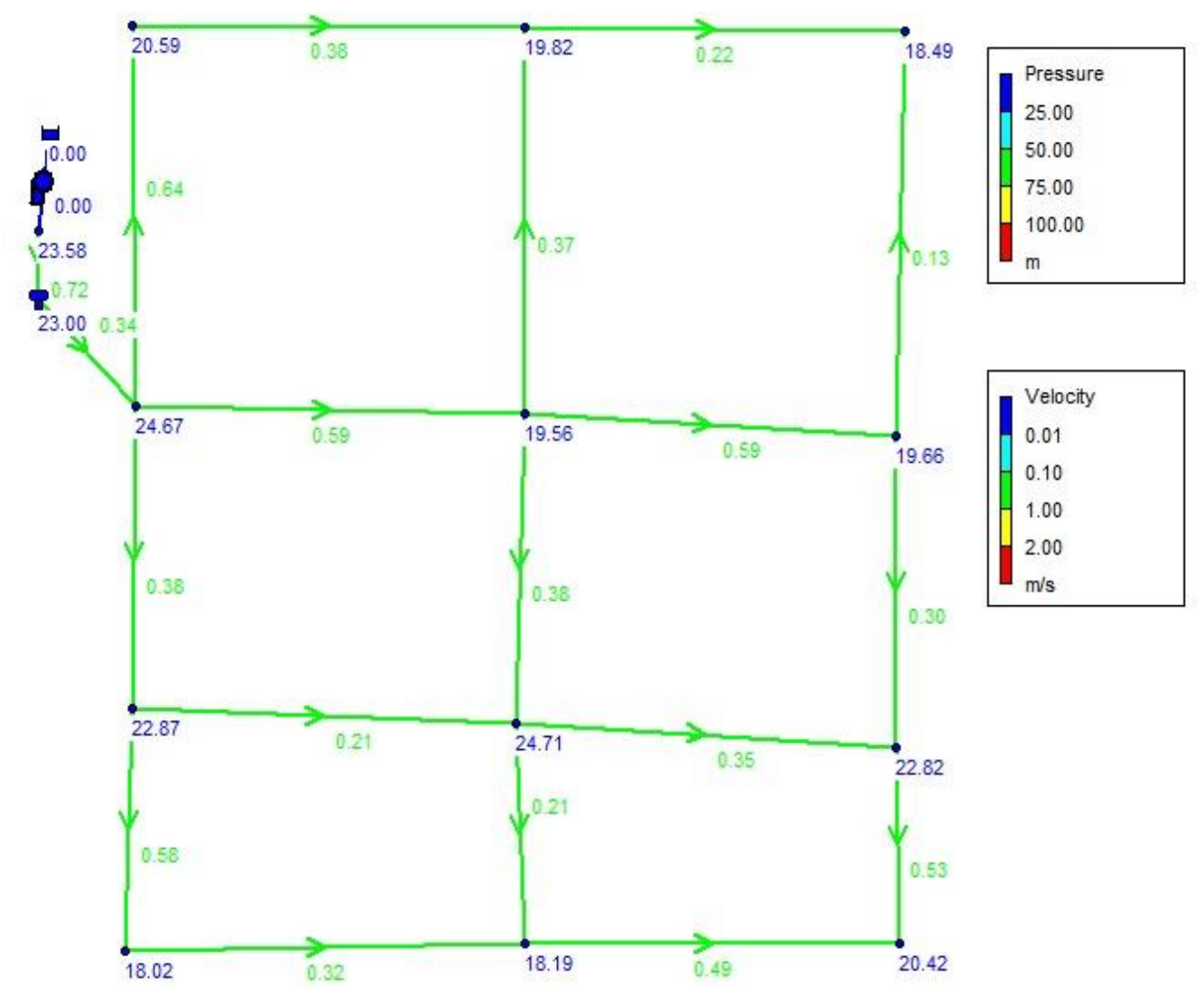

Figure 1. Pipe Distribution System by Epanet 2.0 software 
Table 3: Hourly consumption demand

\begin{tabular}{|c|c|c|c|c|c|c|c|c|c|c|c|c|c|}
\hline Time & $0-1$ & $1-2$ & $2-3$ & $3-4$ & $4-5$ & $5-6$ & $6-7$ & $7-8$ & $8-9$ & $9-10$ & $\begin{array}{c}10- \\
11\end{array}$ & $\begin{array}{c}11- \\
12\end{array}$ & $\begin{array}{c}12- \\
13\end{array}$ \\
\hline $\begin{array}{c}\text { Qconsumption } \\
(\%)\end{array}$ & 1.5 & 1 & 0.5 & 1.5 & 2 & 3.5 & 8 & 19 & 5 & 3 & 4 & 8 & 5 \\
\hline$\Sigma Q_{\text {hmax }}(\%)$ & 1.5 & 2.5 & 3 & 4.5 & 6.5 & 10 & 18 & 37 & 42 & 45 & 49 & 57 & 62 \\
\hline Time & $\begin{array}{c}13- \\
14\end{array}$ & $\begin{array}{c}14- \\
15\end{array}$ & $\begin{array}{c}15- \\
16\end{array}$ & $\begin{array}{c}16- \\
17\end{array}$ & $\begin{array}{c}17- \\
18\end{array}$ & $\begin{array}{c}18- \\
19\end{array}$ & $\begin{array}{c}19- \\
20\end{array}$ & $\begin{array}{c}20- \\
21\end{array}$ & $\begin{array}{c}21- \\
22\end{array}$ & $\begin{array}{c}22- \\
23\end{array}$ & $\begin{array}{c}23- \\
24\end{array}$ & & Sum \\
\hline $\begin{array}{c}\text { Qconsumption } \\
(\%)\end{array}$ & 3 & 2 & 3 & 4.5 & 3 & 8 & 5 & 3.5 & 2.5 & 2 & 1.5 & & 100 \\
\hline$\Sigma Q_{\text {hmax }}(\%)$ & 65 & 67 & 70 & 74.5 & 77.5 & 85.5 & 90.5 & 94 & 96.5 & 98.5 & 100 & & \\
\hline
\end{tabular}

To find the discharge of the system we need to find the percent of (Qin):

$$
\text { Qdaily }=(1000 * 5 * 300) / 1000=1500 \mathrm{~m}^{3} / \text { day }
$$

Rate of hourly:

$$
\begin{aligned}
& \qquad Q_{d}(\%)=\frac{100}{\text { Sum of pump working hours }} * \text { pump working hours } \\
& \text { Volume of the tank }(\%)=\text { Maximum } \mathrm{S}\left(\mathrm{Q}_{\text {in- }}-\mathrm{Q}_{\text {out }}\right)(\%)+\mid \text { Minimum } \mathrm{S}\left(\mathrm{Q}_{\text {in- }}-\mathrm{Q}_{\text {out }}\right)(\%) \mid \\
& \text { Volume of the tank }=(\text { Volume of the tank } \%) * \text { Daily water demand }
\end{aligned}
$$

\begin{tabular}{|c|c|c|c|c|}
\hline No of pumps & Iteration & Working hours of the Pumps & $\mathrm{V}_{\min }$ of $\operatorname{tank}(\%)$ & $\mathrm{V}_{\min } \mathrm{m}^{3} /$ day \\
\hline \multirow{3}{*}{2} & A & 27 & 12.18 & 182.7 \\
\hline & $\mathrm{B}$ & 25 & 11 & 165 \\
\hline & $\mathrm{C}$ & 26 & 13.58 & 203.7 \\
\hline \multirow{3}{*}{3} & $\mathrm{~A}$ & 30 & 9 & 135 \\
\hline & $\mathrm{B}$ & 20 & 10 & 150 \\
\hline & $\mathrm{C}$ & 34 & 11.18 & 167.7 \\
\hline \multirow{3}{*}{4} & A & 31 & 6.1 & 91.5 \\
\hline & $\mathrm{B}$ & 27 & 7.63 & 114.45 \\
\hline & $\mathrm{C}$ & 45 & 15.05 & 225.75 \\
\hline
\end{tabular}

For the best choice $($ Volume of the tank $\%)=6.1 \%$. Volume of the tank $=6.1 \% * 1500=91.5 \mathrm{~m}^{3}$.

Table 4: Result of iterations

For this task, nine trials were done by using (2, 3, and 4) pumps, each pump with three iterations. Table 4 is the result of the iteration.

To choose the best case, we have to focus on the volume of the tank and the working hours of the pumps. In iteration $(3 \mathrm{~B})$, the number of working hours of the pump is in the lowest value, but the volume of the tank is high, therefore, the best trial is (4 A) because the volume of the tank is minimum and the number of working hours of the pumps is good. 


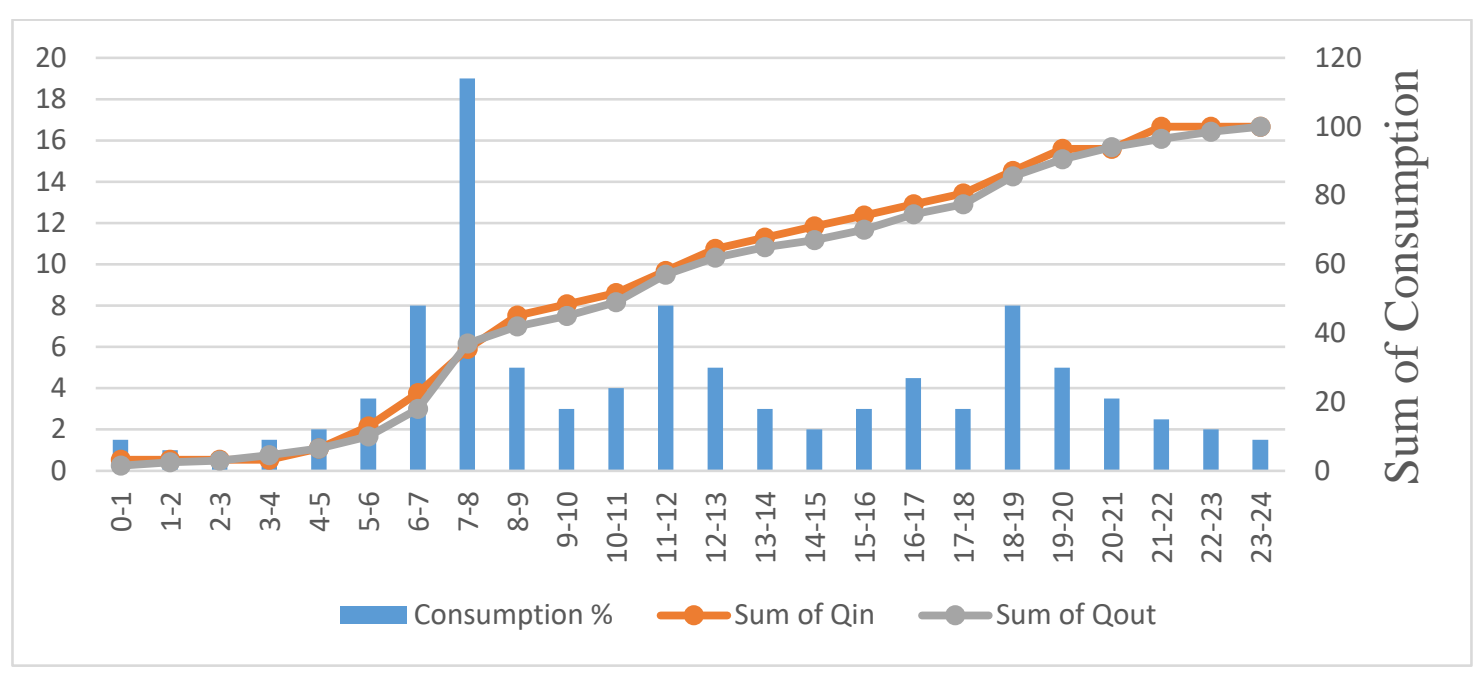

Figure 2. Iteration A while using 4 Pumps

\section{Summary and conclusions}

This study presented the designing of a water distribution system as a case study in Erbil and optimizing it by finding the minimum volume for the tank to minimize the project cost comparing to the pumps working hours. In the beginning, the problem was defined and analyzed by using the 5 whys technic to reach the problem root. After that, designing the pipe distribution system and finding the most efficient design for the volume of elevated tank and pumps working hours was done to minimize the cost. Epanet 2.0 software was used to design the pipe distribution system and to find the most suitable diameter for the pipe system with enough pressure and velocity in each of the junctions. Excel also was used to make the optimization by implementing 9 iterations to get the best tank volume and pump working hours. As it was found, trial $4 \mathrm{~A}$ was the best one because it gave the smallest value of the tank volume with suitable pumps working hours.

\section{References}

[1] Choi, Y.H., Lee, H.M., Choi, J., Yoo, D.G., Kim, J.H. (2019) Development of Practical Design Approaches for Water Distribution Systems, Applied sciences-Basel 9(23). https://doi.org/10.3390/app9235117

[2] Shende, S., Chau, K.W. (2019) Design of water distribution systems using an intelligent simple benchmarking algorithm with respect to cost optimization and computational efficiency, Water science and technology-water supply 19(7): 1829-1898. https://doi.org/10.2166/ws.2019.065

[3] Cisty, M. (2010) Hybrid Genetic Algorithm and Linear Programming Method for Least-Cost Design of Water Distribution Systems. Water resources management 24(1): 1-24. https://doi.org/10.1007/s11269-009-9434-1

[4] Olsson, R.J., Kapelan, Z., Savic, D.A. (2009) Probabilistic building block identification for the optimal design and rehabilitation of water distribution systems. Journal of hydroinformatics 11(2): 89-105. https://doi.org/10.2166/hydro.2009.047 
[5] Ostfeld, A., Tubaltzev, A. (2008) Ant colony optimization for least-cost design and operation of pumping water distribution systems. Journal of water resources planning and management. 134(2): 107-118. https://doi.org/10.1061/(ASCE)0733-9496(2008)134:2(107)

[6] Judice, J.J., Silva-Afonso, A., Baptistac, C.P., Fernandes, L.M. (2008) Economic design of water distribution systems in buildings. Engineering optimization. 40(8): 749-766. https://doi.org/10.1080/03052150802054035

[7] Babayan, A.V., Kapelan, Z.S., Savic, D.A., Walters, G.A. (2006) Comparison of two methods for the stochastic least cost design of water distribution systems. Engineering optimization. 38(3): 281-297. https://doi.org/10.1080/03052150500466846

[8] Kapelan, Z.S., Savic, D.A., Walters, G.A. (2005) Multiobjective design of water distribution systems under uncertainty. Water resources research. 41(11). https://doi.org/10.1029/2004WR003787

[9] Gungor-Demirci, G., Lee, J., Keck, J. (2020) Optimizing pump operations in water distribution systems: energy cost, greenhouse gas emissions and water quality. Water and environment journal. https://doi.org/10.1111/wej.12583

[10] Mogtit, A., Aribi, N., Lebbah, Y., Lagha, M. (2020) Equitable optimized airspace sectorization based on constraint programming and OWA aggregation. Aircraft engineering and aerospace technology. 92(8): 1225-1243. https://doi.org/10.1108/AEAT-04-2019-0080 
Mohammed Amin, O.K., Akkad, M.Z., Bányai, T.

Designing of water distribution system

\section{Appendix}

Table 5: Iteration A with 4 Pumps

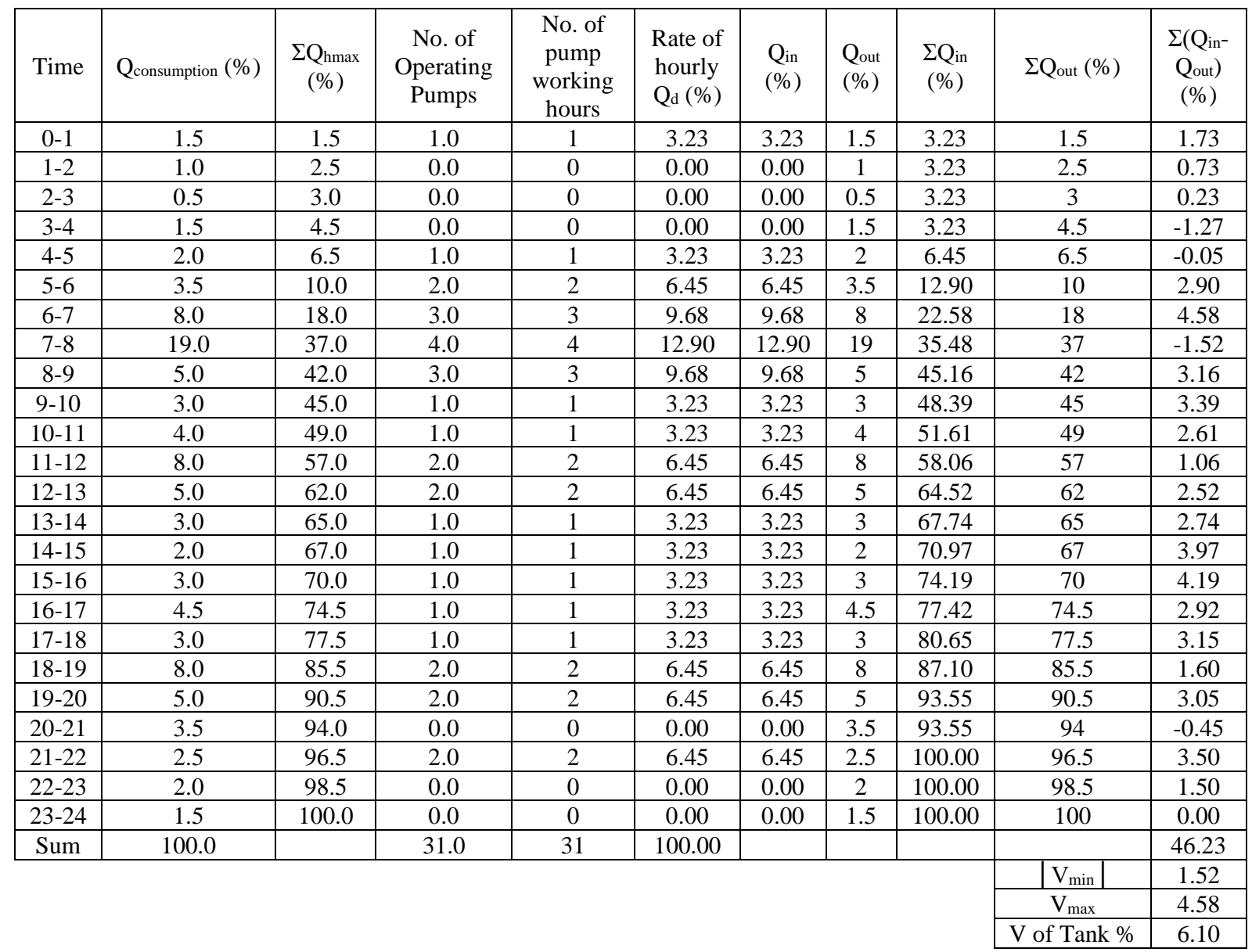

